\title{
Bigger is not always better: Offspring size does not predict growth or survival for seven ascidian species
}

\author{
Molly W. Jacobs ${ }^{1,2,4}$ AND Kristin M. Sherrard ${ }^{2,3}$ \\ ${ }^{1}$ Department of Biology, Woods Hole Oceanographic Institution, Woods Hole, Massachusetts 02543 USA \\ ${ }^{2}$ Friday Harbor Laboratories, 620 University Road, Friday Harbor, Washington 98250 USA \\ ${ }^{3}$ Department of Molecular Genetics and Cell Biology, University of Chicago, Chicago, Illinois 60637 USA
}

Abstract. The presumed trade-off between offspring size and quality predicted by life history theory is often invoked to explain the wide range of propagule sizes observed in animals and plants. This trade-off is broadly supported by intraspecific studies but has been difficult to test in an interspecific context, particularly in animals. We tested the fitness consequences of offspring size both intra- and interspecifically for seven species of ascidians (sessile, suspension-feeding, marine invertebrates) whose offspring volumes varied over three orders of magnitude. We measured two major components of fitness, juvenile growth rates and survival, in laboratory and field experiments encompassing several food conditions. Contrary to the predictions of life history theory, larger offspring size did not result in higher rates of growth or survival, and large offspring did not perform better under nutritional stress, either intraspecifically or interspecifically. In fact, two of the four species with small offspring grew rapidly enough to catch up in size to the species with large offspring in as little as eight weeks, under wild-type food conditions. Trade-offs between growth potential and defense may overwhelm and obscure any trade-offs between offspring size and survival or growth rate. While large initial size may still confer a competitive advantage, we failed to detect any consequences of interspecific variation in initial size. This implies that larger offspring in these species, far from being inherently superior in growth or survival, require compensation in other aspects of life history if reproductive effort is to be efficient. Our results suggest that the importance of initial offspring size is context dependent and often overestimated relative to other life history traits.

Key words: ascidian; growth rate; offspring size; size-quality tradeoff; survival; tunicate.

\section{INTRODUCTION}

Life history theory often assumes a trade-off between offspring number and quality. The lower fecundity imposed by production of larger offspring is thought to be off-set by the higher individual fitness of the offspring, so that greater parental investment per offspring is correlated with greater survival, higher growth rates, or an increase in some other fitness parameter for individual offspring, both intraspecifically and interspecifically (Vance 1973, Smith and Fretwell 1974, Christiansen and Fenchel 1979). This premise has been widely accepted and supported by evidence from intraspecific studies of diverse taxa (reviewed in Marshall and Keough 2008, although see also Karlsson and Wiklund 1984, Litvak and Leggett 1992, Tejedo 1992).

A trade-off between offspring size and number is often invoked to explain broad, interspecific patterns of life history evolution (e.g., Leishman and Westoby 1994, McEdward and Janies 1997, Rees and Westoby 1997,

Manuscript received 5 November 2009; revised 9 April 2010; accepted 13 April 2010. Corresponding Editor: P. T. Raimondi.

${ }^{4}$ Present address: Department of Biology, McDaniel College, 2 College Hill, Westminster, Maryland 21157 USA.E-mail: mjacobs@mcdaniel.edu
Levitan 2000). Currently, the strongest empirical evidence in support of an interspecific trade-off between offspring size and number comes from studies of plants. Plant species with large seeds have higher establishment success (Turnbull et al. 1999, Dalling and Hubbell 2002), a competitive advantage (Turnbull et al. 1999), and a higher tolerance for shade (Mazer 1989, Westoby et al. 1992, Leishman and Westoby 1995, Paz et al. 1999) compared to species with smaller seeds. Species with larger seeds and shoots may also have higher survival (Dalling and Hubbell 2002, Moles et al. 2003, but see also Hodkinson et al. 1998, Paz et al. 2005). However, logarithmic (Gross 1984) and size-specific or relative (Maranon and Grubb 1993, Paz et al. 2005) growth rates are lower for shoots from species with large seeds and seed development time is longer (Moles and Westoby 2003).

Like plants, different species of marine invertebrates produce a wide size range of propagules. Theoretical work has, to a large extent, focused on the consequences of variation in initial egg size for fitness of embryos and larvae (e.g., Vance 1973, Christiansen and Fenchel 1979). Though feeding larvae complicate predictions for many marine taxa (Strathmann 1990), egg size or energy content is a good predictor of size or energy 
content at metamorphosis for diverse lecithotrophic taxa including echinoderms (Lawrence et al. 1984, McClintock and Pearse 1986), ascidians (Berrill 1935), and cone snails (Perron 1981), and even for some planktotrophic crustaceans (reviewed in Strathmann 1977). For these taxa, a large portion of the energy found in the egg is retained in the juvenile, so that fitness consequences of variation in initial size are as likely to be observed in the early juvenile as in the larval stage.

Despite the large number of intraspecific studies on invertebrates, there have been surprisingly few studies that test the prediction of higher individual fitness for larger offspring in an interspecific context. Emlet and Hoegh-Guldberg (1997) studied the sea urchin Heliocidaris erythrogramma and its congener $H$. tuberculata, and found that juveniles from larger eggs were larger and grew faster both intra- and interspecifically. Similarly, Perron (1986) found that postmetamorphic survival of juvenile cone snails in the first year was two orders of magnitude greater for a lecithotrophic species with large eggs compared to a planktotrophic species with small eggs. Interspecific studies have been criticized in concept (e.g., Marshall and Keough 2008) because evolutionary relatedness between species can confound any attempt to infer that observed variation in offspring size is the result of selection, and because these phylogenetic constraints are often not explicitly addressed. However, relatedness does not confound the underlying life history problem: species that differ dramatically in fecundity must compensate for those differences somewhere in the life cycle, assuming populations are at equilibrium. When less fecund species also have larger offspring (Smith and Fretwell 1974, Stearns 1992), higher relative offspring quality is an obvious and commonly assumed explanation.

We tested the hypothesis of an interspecific offspring size-quality trade-off using ascidians. Members of class Ascidiacea within the Tunicata produce morphologically similar, short-lived, lecithotrophic larvae varying in volume over three orders of magnitude (Berrill 1935). All ascidians filter feed using branchial baskets lined with mucus webs, and specialize in small particle sizes throughout their lives (Sherrard and LaBarbera 2005a). Solitary ascidians are highly fecund and produce relatively small offspring, while colonial ascidians have lower annual fecundity but produce substantially larger offspring (Berrill 1935, Tarjuelo and Turon 2004). We chose seven co-occurring species with diverse offspring sizes, from a broad phylogenetic range, and encompassing at least two independent origins of coloniality (Swalla et al. 2000, Turon and Lopez-Legentil 2004).

We measured post-metamorphic growth rates, sizes, carbon contents, and survival under a range of environmental conditions. We found no evidence of a trade-off between offspring size and any of these measures of fitness. Our work suggests that the importance of offspring size may be overestimated in many life history models.

\section{Methods \\ General methods}

Reproductively active adults of seven ascidian species, chosen based on availability, were collected from floating docks in the vicinity of Friday Harbor Laboratories (FHL), Washington, USA, and maintained in flow-through seawater tables at $11-13^{\circ} \mathrm{C}$ until spawning. We dissected gonads, mixed gametes of at least five individuals, and cultured embryos of freespawning species (Cloney 1987), and collected larvae released from brooding species. The species spanned two orders of magnitude in initial settler size and two taxonomic orders. Molecular and morphological analyses have long supported the Pleurogona (a group also commonly referred to by its sole suborder, the Stolidobranchiata) as a monophyletic group (Swalla et al. 2000). The relative positions and monophyly of the Aplousobranchiata and Phlebobranchiata, the two remaining ascidian suborders, are unclear, and the taxonomic assignment of the families Cionidae and Diazonidae to one or the other suborder is still debated (reviewed by Turon and Lopez-Legentil 2004). We consider the aplousobranchs and the phlebobranchs together here as order Enterogona (Garstang 1928, Berrill 1950, Kott 1985), although we caution that significant phylogenetic work remains to be done on these diverse groups.

The species with the smallest settlers were the solitary pleurogonids Boltenia villosa $\left(0.003 \pm 0.001 \mathrm{~mm}^{3}\right.$ [mean $\pm \mathrm{SD}])$ and Styela gibbsii $\left(0.008 \pm 0.002 \mathrm{~mm}^{3}\right)$, and the solitary enterogonids Corella inflata $(0.005 \pm 0.002$ $\left.\mathrm{mm}^{3}\right)$ and Ciona savigni $\left(0.027 \pm 0.010 \mathrm{~mm}^{3}\right)$. The colonial enterogonids Diplosoma macdonaldi (0.185 \pm $\left.0.043 \mathrm{~mm}^{3}\right)$ and Distaplia occidentalis $(0.466 \pm 0.123$ $\mathrm{mm}^{3}$ ) were larger, and the colonial pleurogonid Botrylloides violaceus was by far the largest (3.199 \pm 1.427 $\mathrm{mm}^{3}$ ). Hereafter, we refer to species by genus name only to avoid confusion, and indicate the four species with the smallest settlers with asterisks (e.g., *Boltenia), and the three species with the largest settlers with "plus" symbols (e.g., ${ }^{+}$Botrylloides).

\section{Feeding experiment}

Larvae were settled on roughened, gridded black plexiglas plates $(3 \times 5 \mathrm{~cm})$. We culled excess individuals from plates, retaining 11 to 12 individuals per plate on 9 ("Styela, *Boltenia), 12 ("Ciona), or 15 ("Corella) plates for small settlers and two to six individuals per plate on $11\left({ }^{+}\right.$Diplosoma $)$or $21\left({ }^{+}\right.$Distaplia,${ }^{+}$Botrylloides $)$plates for large settlers. Sample sizes were based on larval availability $\left({ }^{+}\right.$Diplosoma) or survival in a pilot experiment. Individuals were selected for culling based on location, so that remaining juveniles were as broadly spaced as possible to avoid crowding. Because ascidian larvae are non-feeding, settler size is closely correlated with larval size (see Marshall and Keough 2005, Marshall et al. 2006). 


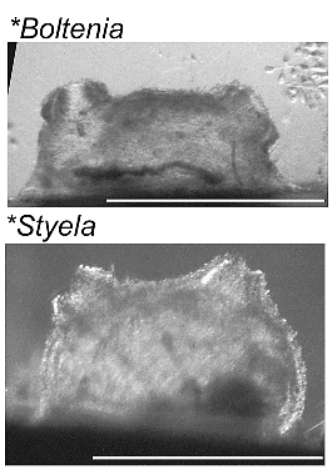

${ }^{+}$Distaplia

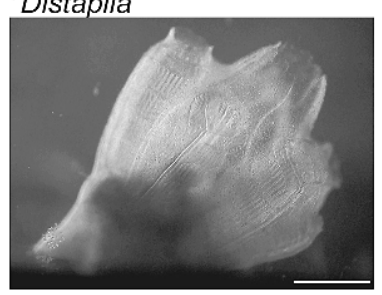

${ }^{*}$ Ciona

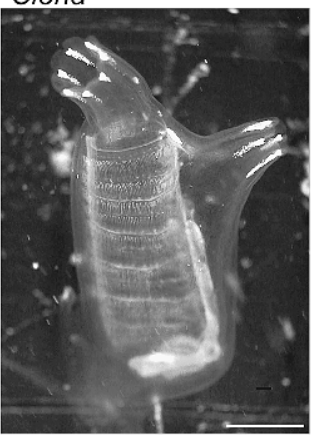

${ }^{*}$ Corella

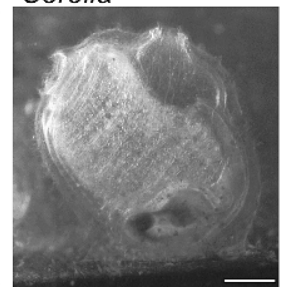

${ }^{+}$Diplosoma

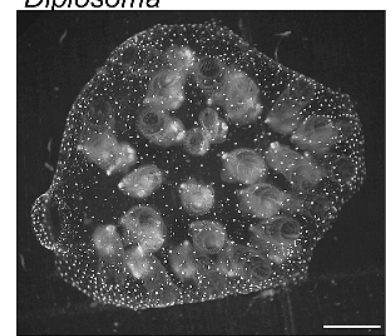

${ }^{+}$Botrylloides

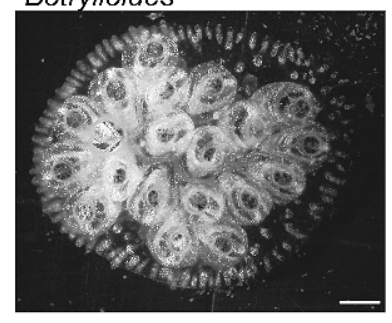

Plate 1. Juvenile ascidians after eight weeks of growth in the Normal Food treatment. All scale bars are 1 mm. Photo credits: M. W. Jacobs and K. M. Sherrard.

Time from larval settlement to commencement of juvenile feeding varies among these species from a few hours $\left({ }^{+}\right.$Distaplia $)$to eight days $\left({ }^{*}\right.$ Boltenia) . The period between settlement and commencement of feeding is characterized by rapid expansion of body volume, and so we chose to measure initial volume at commencement of feeding in order to avoid confounding variation in initial volume with variation in developmental stage. This also allowed us to synchronize initiation of feeding with the start of food treatments for all species. Because it was not possible to take the initial photographs of every individual on a single day, timing of settlement was staggered so that ${ }^{*}$ Styela and "Boltenia were photographed and commenced feeding on the first day, ${ }^{*}$ Corella and ${ }^{*}$ Ciona on the second day, and ${ }^{+}$Distaplia, ${ }^{+}$Diplosoma, and ${ }^{+}$Botrylloides on the third and fourth days. Final measurements were taken over a two-day period, so that total length of the experiment was 58-59 days for all individuals.

Plates were affixed to paddles submerged in 9-L plastic aquaria, with three paddles and 12 plates per tank, and three replicate tanks per treatment for a total of nine tanks. Paddles were stirred by motors at $6 \mathrm{rpm}$ (Strathmann 1987). Paddle excursion was approximately $10 \mathrm{~cm}$ at their ends. We distributed species evenly among the paddles and tanks and maintained the experiment in the dark at $12^{\circ} \mathrm{C}$. The three food treatments were low food $(0.45-\mu \mathrm{m}$ filtered seawater; bacteria and other small organic matter), normal food (35- $\mu \mathrm{m}$ filtered water from the FHL outer breakwater, an approximation of "wild" conditions), and high food (normal food water supplemented with $1.25 \times 10^{4}$ cells/ $\mathrm{mL}$ of cultured Isochrysis algae, centrifuged to remove algal growth medium after Paulay et al. 1985). Isochrysis algae were readily consumed by juvenile *Boltenia, ${ }^{*}$ Corella,${ }^{+}$Distaplia, and ${ }^{+}$Botrylloides in a pilot experiment. We changed the water completely and replenished food every second day, rotating plates systematically among paddles, tanks, and stirring systems to minimize paddle and tank effects.

\section{Measurement of volume, volumetric growth rates, total carbon content, and survival}

We photographed all individuals in top and side views when feeding commenced (week 0) and after 58-59 days (week 8; see Plate 1), using a digital camera attached by a C-mount adapter to a dissecting trinocular microscope and a submerged right angle prism to obtain side views. We also haphazardly chose a subsample of individuals to re-photograph on days $10-11,23-24$, and 38-39. We measured size by estimating volume in order to minimize error from differences in shape between species or developmental stages. Volumes and volume-based logarithmic and size-specific growth rates (based on initial and final volumes) were calculated as described in Appendix A. As an independent measure of size, we measured equivalent carbon contents for all individuals at the end of the experiment using dichromate oxidation as described in McEdward and Carson (1987). See Appendix B for more detailed methods and a discussion of the relevance of this technique to the current study.

\section{Survival in the field}

We intermingled competent larvae of six ascidian species and allowed them to settle on gridded plexiglas plates. Each plate contained at least three species, and spaces around colonial individuals were culled to prevent them from overgrowing or fusing with neigh- 
bors. Sample sizes (number of plates, mean settlers/ plate) for *Boltenia (18, 49), "Corella (27, 24), ${ }^{+}$Botrylloides $(27,3),{ }^{+}$Distaplia $(32,3)$, and ${ }^{+}$Diplosoma $(32,4)$ were chosen based on survival in a pilot experiment, but sample size for ${ }^{*}$ Styela $(15,4)$ was a consequence of limited larval availability. Prior to explant, we photographed and measured initial colony area in top view for one haphazardly chosen individual per plate for ${ }^{+}$Botrylloides and ${ }^{+}$Diplosoma. Initial size could not be accurately measured for ${ }^{*}$ Boltenia, ${ }^{*}$ Styela, and ${ }^{*}$ Corella because their branchial baskets were not fully expanded so soon after settlement, and ${ }^{+}$Distaplia was excluded because length or area in top view did not correlate well with total volume (M. W. Jacobs and K. M. Sherrard, unpublished data). Plates were explanted within 24 hours of settlement, each protected either by a cage or a partial cage (mesh size $1 \mathrm{~cm}$, open on one side only) $3 \mathrm{~m}$ underwater from the FHL outer floating breakwater. We did not have sufficient sample sizes to include a completely cage-free treatment, and so although the partially caged treatment controls for the effects of predation, it may not reflect survival in the absence of any cage structures. All of the species included in this portion of the study commonly cooccur on floating docks in this location. We monitored survival at weekly intervals for four weeks by inspecting plates under a dissecting microscope.

\section{Data analysis}

All statistical analyses were performed in JMP 5.1.2 (SAS Institute, Cary, North Carolina, USA). We transformed proportion survival data by $\arcsin (\operatorname{sqrt}[x])$ and specific (relative) growth rates, volumes, initial volumes, and total carbon contents by $\log (x)$ in order to normalize distributions and homogenize the variances. Logarithmic growth rates were left untransformed. Where multiple individuals shared a single plate, responses were averaged for that plate, so that plate was the unit of replication for all statistical analyses (see Appendix C for sample sizes).

For interspecific comparisons of final volume, carbon content, logarithmic growth rates, and specific growth rates, species $(N=6)$ was a random, blocking factor whereas food level (high, normal, or low) and initial size category (large or small) were fixed factors in four separate two-factor, standard least squares, restricted maximum likelihood (Searle et al. 1992) analyses of variance. To make sure phylogenetic effects did not obscure initial size effects, we also included order as a fixed factor (Harvey and Pagel 1991). ${ }^{+}$Diplosoma was excluded by design from the high-food treatment because of limited larval availability, and by circumstance from the low-food treatment because of complete mortality. In order to compare performance of ${ }^{+}$Diplosoma to other species, we ran reduced versions of all four analyses for the normal-food treatment, with initial size category and order as fixed factors and species as a random factor. We adjusted $\alpha$ values for these reduced analyses to account for multiple testing. In the carbon content data set, "Boltenia in the normalfood treatment and *Boltenia and *Corella in the lowfood treatment fell below the minimum detectable level and were excluded from the analysis.

We used separate standard least squares regressions for each species to test whether initial volume predicted final volume or carbon content intraspecifically, with food level included as an indicator variable. We calculated power to detect an effect of initial size for each intraspecific regression based on effect sizes observed in the literature of $20 \%$ for volume data (Marshall et al. 2006) and 50\% for carbon content data (Qian and Chia 1991, Reitzel et al. 2005).

All species except *Boltenia and *Styela experienced $100 \%$ mortality by week four in the partially caged treatment of the survival experiment, and so we calculated proportion survival for each plate in the caged treatment and compared survival interspecifically using initial size category $(N=2)$ and order $(N=2)$ as fixed factors and species $(N=6)$ as a random blocking variable. We also used analysis of covariance to test whether survival (included as a binomial response variable) varied intraspecifically as a function of initial size for ${ }^{+}$Botrylloides $(N=16$ plates $)$ and ${ }^{+}$Diplosoma $(N$ $=17$ plates).

\section{RESUlts}

Detailed statistical results are provided in Appendix C: Tables C1-C4.

\section{Initial size did not predict final size or growth rate}

Within species, initial volume did not predict final volume (Fig. 1A; Table C1) or carbon content (Fig. 1B; Table C2) for any of the seven species tested, regardless of food treatment. Similarly, initial size category did not explain variation among species in final size (Fig. 2A; $P$ $=0.1463 ;$ Table C3), carbon content (Fig. 2B; $P=$ 0.1443; Table C3), logarithmic growth rate (Fig. 2C; $P=$ 0.4496; Table C3), or size specific growth rates (Fig. 2D; $P=0.4273$; Table C3). Power was high $(>0.90)$ for all intraspecific analyses except for ${ }^{+}$Distaplia volume data (0.67), and for those analyses with small sample sizes $\left({ }^{*}\right.$ Corella,${ }^{+}$Diplosoma volume and carbon content, and *Boltenia carbon content; Tables C1, C2). We observed a significant interaction between initial size category and food treatment for final volume (Fig. 2A; $P=0.0054$; Table C3a), size-specific growth rate (Fig. 2D; $P=$ 0.0053; Table C3a), and logarithmic growth rate (Fig. 2C; $P=0.0044$; Table C3a), and a trend for carbon content (Fig. 2B; $P=0.0915$; Table C3a). There was no obvious interaction between initial size and food treatment intraspecifically (Fig. 1), although we did not explicitly test for this.

Enterogonids had higher logarithmic (Fig. 2C; $P=$ 0.0463; Table C3) and size-specific (Fig. 2D; $P=0.0487$; Table C3) growth rates than pleurogonids, and the highest growth rates by far were observed for entero- 

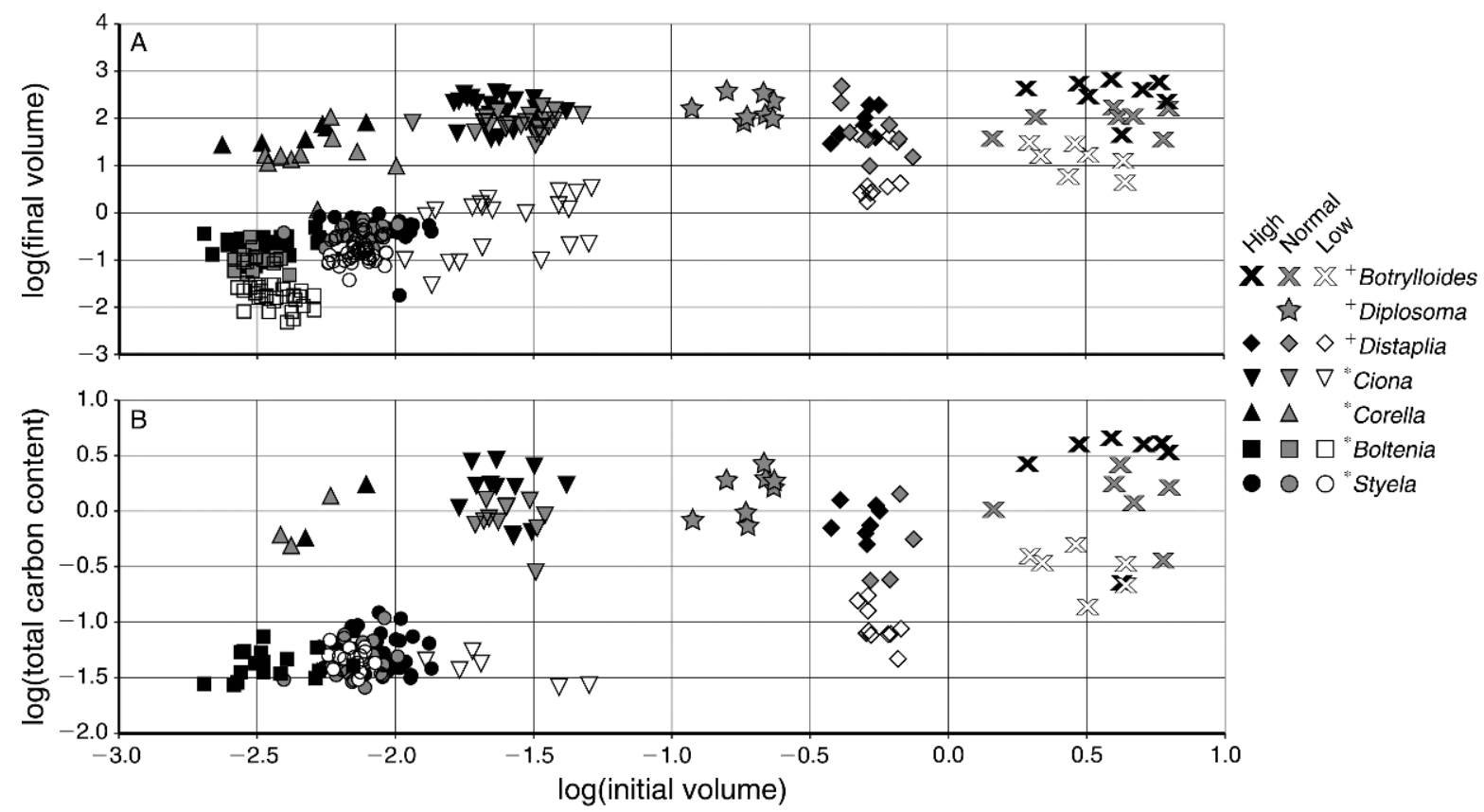

$\Delta \Delta \quad$ "Corella

- $\square$ B Boltenia

- $\bigcirc$ * Styela

FIG. 1. Logarithm of initial volume plotted against the logarithms of (A) final volume or (B) total carbon content for seven ascidian species grown in high food, normal food, or low food. Each point represents one individual. We refer to species by genus name only to avoid confusion, and we indicate the four species with the smallest settlers with asterisks (e.g., ${ }^{*}$ Boltenia), and the three species with the largest settlers with "plus" symbols (e.g., ${ }^{+}$Botrylloides).

gonids * Corella and ${ }^{*}$ Ciona (Fig. 2C, D). Growth rates were generally sigmoid (Fig. 3), with the fastest growth occurring between weeks one and five.

\section{Small species were not more vulnerable} to nutritional stress

Final volumes, logarithmic growth rates, and sizespecific growth rates were significantly lower in low food compared to normal food and high food for all species (Figs. 2 and 3, Table C3); the effect sizes were greatest for ${ }^{*}$ Ciona and least for "Styela (Fig. 2). Carbon contents were also lower in low food compared to normal food and high food, although this difference was not significant for "Styela (Fig. 2; species-specific posthoc tests not shown). Survival decreased sharply in the low-food treatment compared to the normal-food and high-food treatments for ${ }^{+}$Diplosoma $(0 \%),{ }^{*}$ Corella $(50 \%)$, and ${ }^{*}$ Ciona $(51 \%$; Fig. $4 \mathrm{~A}) .{ }^{+}$Diplosoma also experienced relatively low survival $(32 \%)$ in the normalfood treatment. Survival in the laboratory was otherwise high and ranged from $65 \%\left({ }^{+}\right.$Botrylloides, normal food $)$ to $100 \%\left({ }^{+}\right.$Botrylloides and ${ }^{*}$ Styela, low food; Fig. 4A).

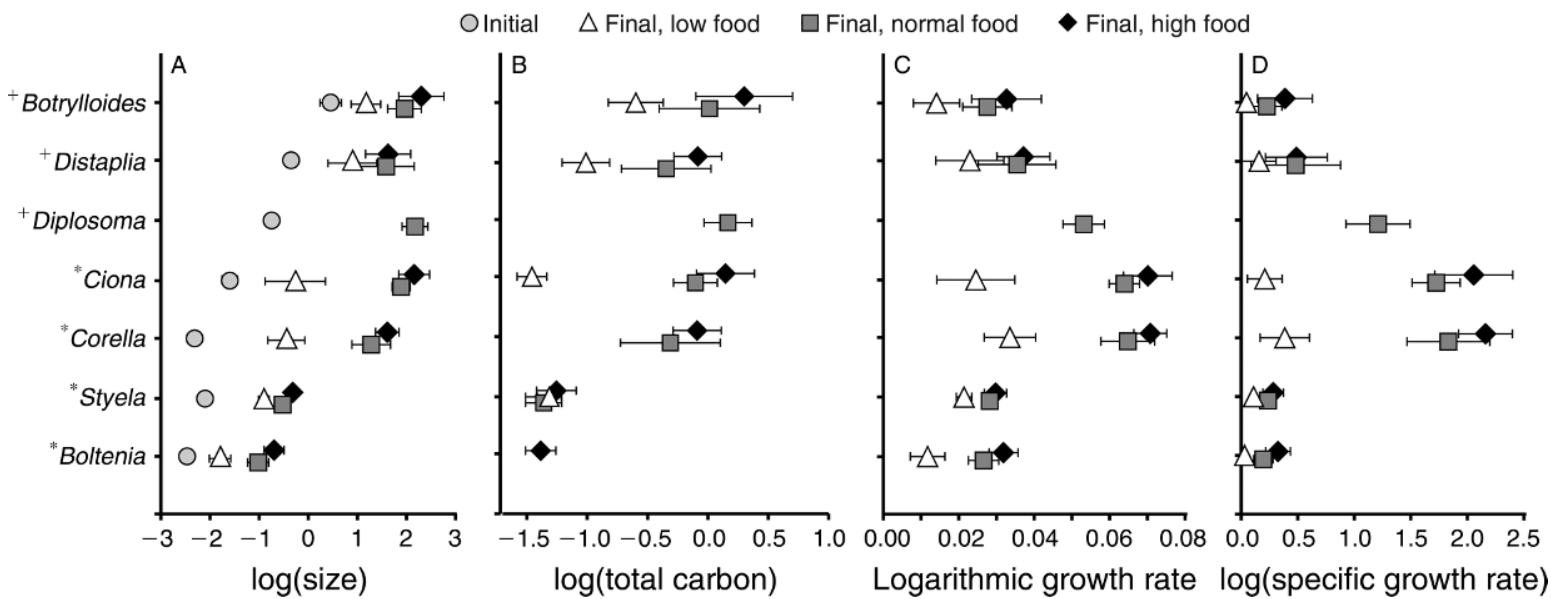

FIG. 2. Mean initial volume, final volume, total carbon content, logarithmic growth rate, and size-specific growth rate for each species in High Food, Normal Food, and Low Food treatments. Error bars are standard deviations. 

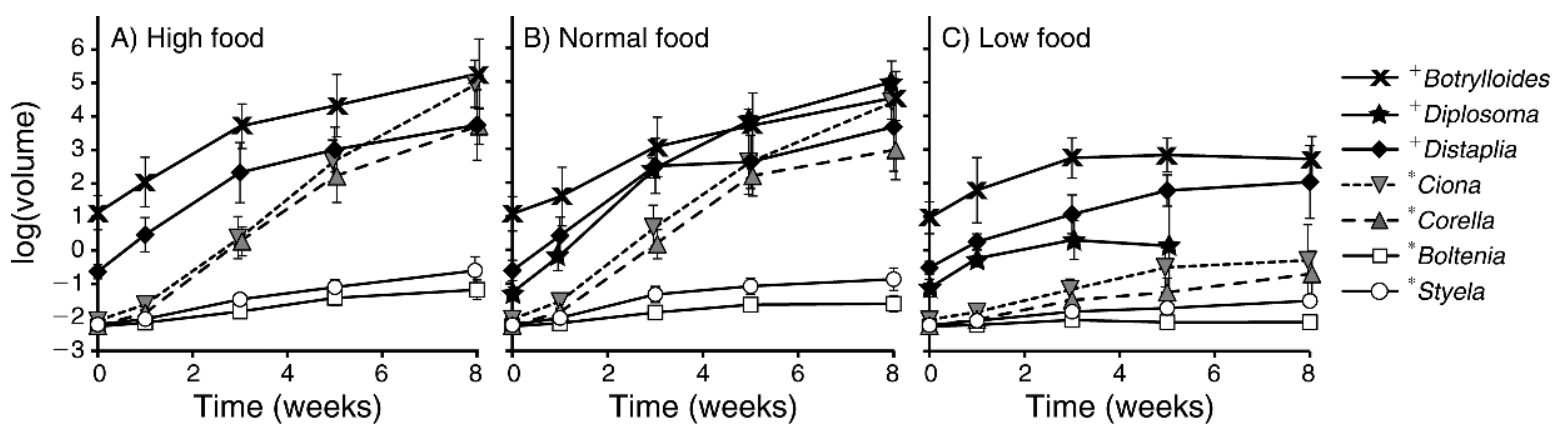

FIG. 3. Change in the logarithm of body volume $\left(\mathrm{mm}^{3}\right)$ over time in (A) high food, (B) normal food, or (C) low food for seven ascidian species. Error bars are standard errors; error bars and points are slightly offset where necessary for visual clarity.

Initial size did not predict survival in the field or vulnerability to predation

In the field, all species except *Boltenia and "Styela experienced $100 \%$ mortality by week four in the partially caged treatment (Fig. 4B). In the caged treatment, survival varied interspecifically as a function of order (Fig. 4C; $P=0.0461$; Table $\mathrm{C} 4$ ) but not initial size category (Fig. 4C; $P=0.5306$; Table C4). Survival was highest for pleurogonids *Boltenia and ${ }^{+}$Botrylloides,

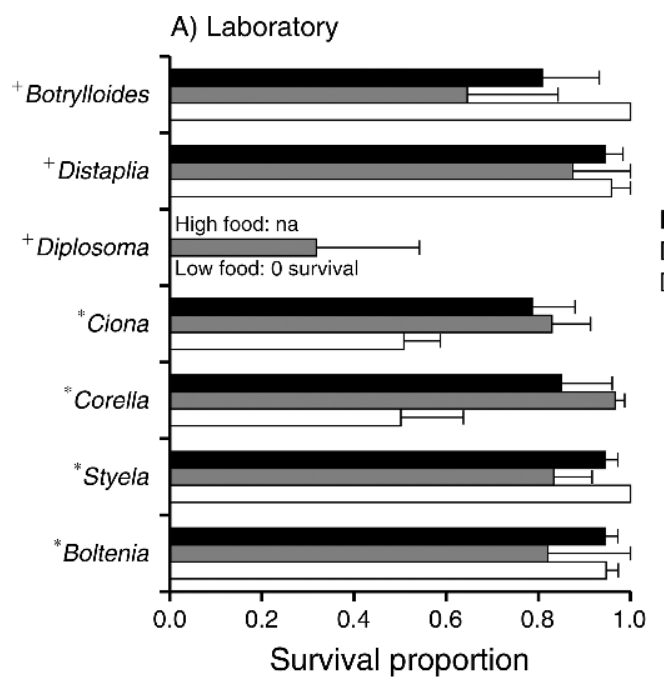

High food

$\square$ Normal food

$\square$ Low food

B) Field, partial cage

C) Field, cage
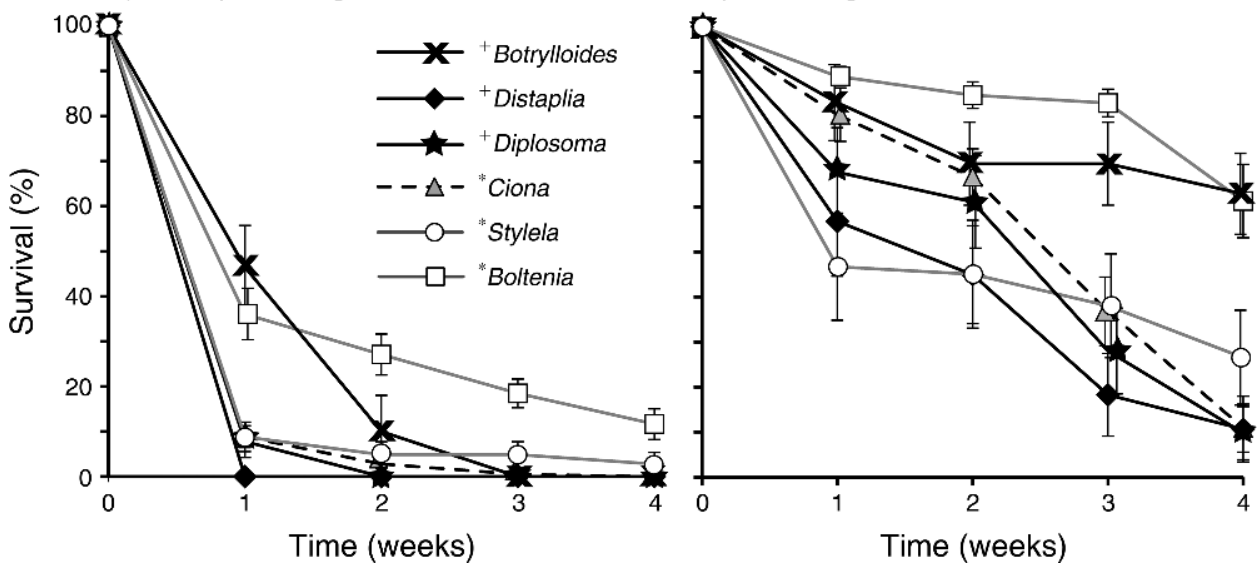

FIG. 4. Proportion survival of juvenile ascidians over (A) eight weeks in the laboratory or four weeks in the field hanging from a floating outer breakwater and protected either by (B) partial cages or $(\mathrm{C})$ full cages. Error bars are standard errors; error bars and points are slightly offset where necessary for visual clarity. 
and lowest for enterogonids ${ }^{+}$Diplosoma,${ }^{+}$Distaplia, and ${ }^{*}$ Corella. Intraspecifically, offspring size was not correlated with survival in the field for ${ }^{+}$Botrylloides $\left(F_{1,14}=\right.$ $0.4181, P=0.5283)$ or $^{+}$Diplosoma $\left(F_{1,15}=0.7035, P=\right.$ $0.4148)$

\section{DiscusSION}

\section{Large offspring did not outperform small offspring interspecifically}

All ascidian species experienced substantial mortality and were vulnerable to predation, but survival in the laboratory and in the field was unrelated to initial size. The best survivors were the species with the very smallest ( ${ }^{*}$ Boltenia) and very largest $\left({ }^{+}\right.$Botrylloides) offspring, and the worst survivors also included species with both small ( ${ }^{*}$ Corella) and large $\left({ }^{+}\right.$Distaplia, ${ }^{+}$Diplosoma) offspring.

The most likely sources of mortality in our field experiment were overgrowth by diatom and algal films (which appeared in the first week), and predation or incidental crushing by mobile predators such as fish or shrimp (Young 1986, Osman and Whitlatch 1996) that could easily navigate the hanging partial cages. Small juveniles are presumably more vulnerable than large juveniles to overgrowth, and slow-growing ones remain so longer, but in our study ${ }^{*}$ Boltenia had the highest survival despite being initially smallest and the slowest grower. Large juveniles may be more vulnerable than small juveniles to visual predators such as fish, although this does not explain the very poor survival of * Corella or the relatively strong performance of ${ }^{+}$Botrylloides in the predation treatment. We followed species in the field for only four weeks, and so it is still possible that juveniles of small, slow-growing species face higher lifetime predation risks or are vulnerable to a wider range of predators as they grow through different size ranges (Osman and Whitlatch 1996).

Plants with small seeds have higher growth rates than plants with large seeds (Maranon and Grubb 1993, Paz et al. 2005), consistent with predictions from animal literature that metabolic rate should scale with $3 / 4$ body mass (reviewed by Hughes and Hughes 1986). The predicted relationship between offspring size and growth rate for ascidians is unclear, however, because ascidian species with large offspring have better developed feeding structures (Berrill 1935) and can have higher size-specific volumetric flow rates during the first week of feeding (Sherrard and LaBarbera 2005b). Reduced access to food as a consequence of smaller feeding structures and life deep in velocity boundary layers (Sherrard and LaBarbera 2005a) may result in lower initial growth rates for small settlers regardless of metabolic rate.

In our data set, neither of these predicted relationships between offspring size and growth rate consistently held true: juveniles of two species with small offspring ("Ciona and "Corella) experienced the highest sizespecific and logarithmic growth rates of all species tested regardless of food treatment, and were among the largest juveniles by week eight in the high-food and normal-food treatments, but juveniles of two other species with small offspring ( ${ }^{*}$ Boltenia and ${ }^{*}$ Styela $)$ grew slowly and remained small for the duration of the experiment, regardless of food treatment. Growth rates among species with large settlers were also variable: ${ }^{+}$Diplosoma grew almost as fast as *Ciona and * Corella, but ${ }^{+}$Distaplia and ${ }^{+}$Botrylloides grew relatively slowly. Remarkably, these differences in growth rate meant that the large $(400 \times)$ differences in volume between species at the start of the experiment were completely erased by week eight except for in the low-food treatment, where all growth rates were lower.

Terrestrial plant species with large seeds survive better and grow faster in shaded conditions than species with small seeds (Leishman and Westoby 1995). In contrast, small offspring in our low-food treatment were not at any consistent disadvantage despite theoretically lower energy reserves. The most dramatic effects of food stress can be seen for ${ }^{*}$ Corella and ${ }^{*}$ Ciona (compare Fig. $3 \mathrm{~A}, \mathrm{C}$ ), but performance of two other small species ( ${ }^{*}$ Boltenia and ${ }^{*}$ Styela) was not affected until late in the experiment. Vulnerability to nutritional stress appeared more closely related to growth potential: the normally fast-growing ${ }^{*}$ Ciona, ${ }^{*}$ Corella, and ${ }^{+}$Diplosoma suffered very low growth rates and high mortality under food stress. The most severe effect of nutritional stress was observed for ${ }^{+}$Diplosoma, which has large offspring but suffered complete mortality in the low-food treatment.

\section{Large offspring did not outperform small offspring intraspecifically}

We were particularly surprised to find that initial offspring size did not affect growth or survival intraspecifically for any of the species we examined, in the laboratory or in the field. In contrast, Marshall and colleagues have found positive correlations between offspring size, growth rate, and survival for ${ }^{+}$Botrylloides (Marshall et al. 2006), and between offspring size and survival for Ciona intestinalis (Marshall and Keough 2003), a congener of * Ciona savigni. We do not have a good overall explanation for the striking differences between our results and previous studies, although methodological differences and environmental heterogeneity may have played a role. We also suspect that negative results (i.e., showing no effect of offspring size) are underestimated in the literature, because they are less likely to be written up or published.

Marshall and colleagues estimated initial size of ${ }^{+}$Botrylloides by measuring projected branchial basket area 24 hours after settlement at $10^{\circ} \mathrm{C}$ and of Ciona intestinalis by measuring body length 24 hours after settlement at $15^{\circ} \mathrm{C}$, in both cases from top view photographs (Marshall and Keough 2003, Marshall et al. 2006). We measured initial volume of ${ }^{+}$Botrylloides and ${ }^{*}$ Ciona savigni based on side and top view photographs at the onset of feeding for each species, 
which occurred after 24 hours at $12^{\circ} \mathrm{C}$ for ${ }^{+}$Botrylloides and after three to four days at $12^{\circ} \mathrm{C}$ for ${ }^{*}$ Ciona savigni. Branchial basket area of ${ }^{+}$Botrylloides correlated well with body volume in our data set (M. W. Jacobs and K. M. Sherrard, unpublished data), and the timing of measurement was similar enough that methodological differences are unlikely to explain the differences in results for this species. Because the period between settlement and the onset of feeding is characterized by rapid expansion of body volume for many ascidian species, including Ciona intestinalis and "Ciona savigni, measurement of size after completion of this initial metamorphic expansion is a more conservative approach than measurement earlier in the postsettlement period. It is possible that the decrease in survival of Ciona intestinalis observed by Marshall and Keough (2003) for small settlers was a consequence of delayed development rather than small offspring size (although see Jacobs et al. 2008). Alternatively, Ciona intestinalis may be more sensitive to variation in offspring size than *Ciona savigni or the six other species in our study.

Several recent studies have found that fitness consequences of intraspecific variation in offspring size were strongly mediated by environmental heterogeneity (e.g., Moran and Emlet 2001, Marshall 2005, Rasanen et al. 2005). Environmental differences between field sites may explain some of the differences in results for ${ }^{+}$Botrylloides, although our field-based mortality rates were similar to or lower than those reported by Marshall and colleagues (Marshall and Keough 2003, Marshall et al. 2006). We could not include the invasive ${ }^{*}$ Ciona in our field study, and so our laboratory-based survival and growth data for ${ }^{*}$ Ciona may not be directly comparable (e.g., Fox 2000, Einum and Fleming 2004) to Marshall and Keough's field-based survival data.

\section{Colonial vs. solitary life histories and offspring size effects: no clear patterns}

Large offspring size is correlated with coloniality in our study, which raises the concern that inherent differences in growth or survival between colonial and solitary organisms could affect interpretation. For example, the growth rates of solitary organisms typically slow with size increase, due to the negative allometric scaling of surface area with volume (reviewed in Hughes and Hughes 1986). Modular growth might free colonial organisms from this constraint (Hughes and Hughes 1986), although the evidence is mixed (e.g., Nakaya et al. 2005, Edmunds 2006; our Fig. 3). The modular construction and regenerative abilities of colonial organisms are also predicted to increase survival relative to solitary organisms (Jackson 1977). Thus, the conflation of large offspring size with coloniality in our dataset increased the probability that we would observe greater survival and faster growth for these species, and consequently increases the robustness of our finding that survival and growth were unrelated to offspring size.
Interspecific variation in offspring size also did not uniformly predict performance within either the solitary or the colonial species. Within the colonial species, ${ }^{+}$Botrylloides had the largest settlers and the highest survival, but was slower growing than ${ }^{+}$Diplosoma. Within the solitary species, "Ciona had the largest settlers and the highest growth rates, but was a poor survivor compared to *Styela and *Boltenia.

\section{Beyond offspring size: alternative correlates of growth and survival}

Offspring size did not predict interspecific or intraspecific variation in survival, final size, or growth rate, but we did observe clear correlations between survival, growth, morphology, and phylogenetic position. Our data show a clear trade-off between growth rate and survival: species with the highest growth rates $\left({ }^{*}\right.$ Corella, ${ }^{+}$Diplosoma) had the highest mortality rates, while species with the slowest growth rates ( ${ }^{*}$ Boltenia, ${ }^{*}$ Styela, ${ }^{+}$Botrylloides) also had the lowest mortality rates. Fastgrowing species in our study were also more vulnerable to nutritional stress, suggesting that fast growers are more sensitive than slow growers to reductions in food supply and should be more vulnerable to geographic and seasonal environmental variation.

Species in this study also differed widely in morphological characters that are likely to affect both survival and growth rate, such as thickness of the tunic, the living exoskeleton of ascidians. For species with small offspring, slow growth was strongly associated with high survival and production of thicker and tougher tunics ( ${ }^{*}$ Boltenia and ${ }^{*}$ Styela). Young $(1985,1986)$ found that juvenile * Boltenia and "Styela produced tunics with 10 times the breaking strength of juvenile ${ }^{*}$ Corella and Chelyosoma productum (another local species), and were also more resistant to gastropod predation and mechanical stresses. Tunic strength is unknown for other species in this study, although Tarjuelo and Turon (2004) found that investment in tunic production (tunic:zooid dry mass ratio) was low for Diplosoma spongiforme compared to most other colonial ascidians. ${ }^{+}$Diplosoma in this study had the thinnest appearing tunic of all the colonial species we studied, but the highest growth rates. Our results are consistent with reports that investment in tunic is correlated interspecifically with longevity (Svane 1983) and growth form, but not with reproductive investment (Tarjuelo and Turon 2004).

Finally, life history strategy was closely tied to phylogeny. Pleurogonids ("Boltenia, "Styela, and ${ }^{+}$Botrylloides), despite spanning a wide range of sizes at settlement, had similarly shaped growth curves, similarly low logarithmic and size-specific growth rates, and similarly high survival. Among enterogonids, ${ }^{+}$Diplosoma, ${ }^{*}$ Corella, and ${ }^{*}$ Ciona, also had similarly shaped growth curves and similarly high logarithmic and size-specific growth rates, and similarly low survival. Results for ${ }^{+}$Distaplia were mixed: the growth curve was intermediate, growth rates were variable but similar to 
those of the pleurogonids, and survival was similar to that of the other enterogonids. Even within taxonomic groups, we still did not observe any consistent effect of offspring size. Among pleurogonids, the species with the smallest offspring ("Boltenia) had the highest survival and the lowest growth rates, while among enterogonids the species with the smallest offspring $\left({ }^{*}\right.$ Corella $)$ had low survival and the highest growth rates.

\section{Why make large offspring?}

We failed to find any evidence that large offspring have higher individual fitness than small offspring using several fundamental metrics of fitness: size, growth rate, and survival under a range of environmental conditions. If there is no intrinsic survival or growth advantage to being larger during the juvenile period, when growth rates and mortality are highest, then the strategy of producing fewer larger offspring requires an alternative explanation.

Both intra- and interspecific studies have revealed strong effects of body size on the outcome of competitive interactions (e.g., Russ 1982, Sebens 1982, Marshall and Keough 2008). We did not measure competitive ability directly, but it is likely that tiny recruits of solitary species are extremely vulnerable to overgrowth by adult neighbors or other, larger recruits. Interestingly, fast-growing species with thin tunics such as * Ciona and "Corella are often among the earliest pioneer species to recruit into open space (Lambert 1968, Andersson et al. 2009), while heavily protected species such as *Boltenia and * Styela appear later in succession (Greene et al. 1983; M. W. Jacobs, unpublished data). The relationship between tunic thickness, offspring size, and vulnerability to overgrowth would be worth exploring in ascidians.

Our study was not designed to measure presettlement fitness consequences of offspring size variation, but these likely play an important role. First, most species that make small offspring are free-spawners and may have lower fertilization rates than species that brood large offspring (Ryland and Bishop 1993, Bolton and Havenhand 1996). High presettlement mortality rates have been reported for large ascidian larvae (Stoner 1990), but planktonic survival could be even lower for small larvae, and probably is inversely correlated with planktonic period (Vance 1973). However, neither of these explanations applies to highly fecund brooders with small offspring such as * Corella (Lambert et al. 1995). Studies comparing presettlement mortality of planktonic larvae as a function of size would provide crucial information, but accurate measurement of planktonic mortality for such small larvae has thus far eluded larval ecologists.

Finally, it is possible that despite much lower instantaneous fecundity (Tarjuelo and Turon 2004), lifetime fecundity is higher for some ascidians with large offspring. However, in temperate areas some solitary species are often extremely long lived (Svane 1983), while many ascidian colonies do not survive the winter (Greene et al. 1983). Lifetime reproductive output has not to our knowledge been quantified for any ascidian species.

\section{Conclusions}

A trade-off between offspring size and number is often invoked to explain broad, interspecific patterns of life history evolution (e.g., Leishman and Westoby 1994, McEdward and Janies 1997, Rees and Westoby 1997, Levitan 2000). Our study is the first major interspecific test of the "bigger is better" hypothesis in marine invertebrates, and one of very few to simultaneously measure intra- and interspecific variation in fitness parameters as a consequence of offspring size across many species. Remarkably, initial size was not correlated interspecifically or intraspecifically with any of the fitness components we measured including survival, growth rate, vulnerability to food stress, or vulnerability to predation.

Our results should be interpreted with some caution: we have tested only seven out of more than 2000 species in Class Ascidiacea, and the predicted positive relationship between offspring size and fitness may yet hold with a larger sample. However, regardless of whether a broader relationship exists, our findings call into question the common assumption that larger offspring must always perform better for a given group of organisms. If large offspring do not outperform small offspring intraspecifically, then selection will tend to favor small offspring, and we speculate that in many cases species that package reproductive effort into fewer, larger offspring are constrained to do so despite selective pressure to maximize offspring number. Our results suggest that the importance of initial offspring size is context dependent and often overestimated relative to other life history traits.

\section{ACKNOWLEDGMENTS}

Authorship order is alphabetical; authors contributed equally to this work. Comments from R. R. Strathmann, M. LaBarbera, C. Pfister, D. Grunbaum, J. Voigt, J. Ruesink, J. Pineda, M. Von Dassow, the WHOI Larval Biology discussion group, J. Havenhand, and four anonymous reviewers greatly improved this manuscript. V. Starczak assisted with statistical analyses. We thank R. R. Strathmann for assistance with experimental design, and the director and staff of Friday Harbor Laboratories for research space and support. Support was provided by an NSF GRF to M. W. Jacobs, an NSF DDIG, SICB Student Research Grant, the University of Chicago Hinds Fund, a Sigma Xi Grant in Aid of Research, and an Alan J. Kohn Fellowship to K. M. Sherrard, and NSF grants OCE 0217304 and IBN 0113603 to R. R. Strathmann.

\section{Literature Cited}

Andersson, M. H., M. Berggren, D. Wilhelmsson, and M. C. Ohman. 2009. Epibenthic colonization of concrete and steel pilings in a cold-temperate embayment: a field experiment. Helgoland Marine Research 63:249-260.

Berrill, N. J. 1935. Studies in tunicate development part III: differential retardation and acceleration. Philosophical Transactions of the Royal Society B 225:255-326. 
Berrill, N. J. 1950. The Tunicata, with an account of the British species. Ray Society, London, UK.

Bolton, T. F., and J. N. Havenhand. 1996. Chemical mediation of sperm activity and longevity in the solitary ascidians Ciona intestinalis and Ascidiella aspersa. Biological Bulletin 190: 329-335.

Christiansen, F. B., and T. M. Fenchel. 1979. Evolution of marine invertebrate reproductive patterns. Theoretical Population Biology 16:267-282.

Cloney, R. A. 1987. Phylum Urochordata, Class Ascidiacea. Pages 607-639 in M. F. Strathmann, editor. Reproduction and development of marine invertebrates. University of Washington Press, Seattle, Washington, USA.

Dalling, J. W., and S. P. Hubbell. 2002. Seed size, growth rate and gap microsite conditions as determinants of recruitment success for pioneer species. Journal of Ecology 90:557-568.

Edmunds, P. J. 2006. Temperature-mediated transitions between isometry and allometry in a colonial, modular invertebrate. Proceedings of the Royal Society B 273:22752281.

Einum, S., and I. A. Fleming. 2004. Environmental unpredictability and offspring size: conservative versus diversified bethedging. Evolutionary Ecology Research 6:443-455.

Emlet, R. B., and O. Hoegh-Guldberg. 1997. Effects of egg size on postlarval performance: experimental evidence from a sea urchin. Evolution 51:141-152.

Fox, C. W. 2000. Natural selection on seed-beetle egg size in nature and the laboratory: variation among environments. Ecology 81:3029-3035.

Garstang, W. 1928. The morphology of the Tunicata, and its bearings on the phylogeny of the Chordata. Quarterly Journal of Microscopical Science 72:51-187.

Greene, C. H., A. Schoener, and E. Corets. 1983. Succession on marine hard substrata: the adaptive significance of solitary and colonial strategies in temperate fouling communities. Marine Ecology Progress Series 13:121-129.

Gross, K. L. 1984. Effects of seed size and growth form on seedling establishment of six monocarpic perennial plants. Journal of Ecology 72:369-387.

Harvey, P. H., and M. D. Pagel. 1991. The comparative method in evolutionary biology. Oxford University Press, Oxford, UK.

Hodkinson, D. J., A. P. Askew, K. Thompson, J. G. Hodgson, J. P. Bakker, and R. M. Bekker. 1998. Ecological correlates of seed size in the British flora. Functional Ecology 12:762-766.

Hughes, D. J., and R. N. Hughes. 1986. Metabolic implications of modularity: studies on the respiration and growth of Electra pilosa. Philosophical Transactions of the Royal Society B 313:23-29.

Jackson, J. B. C. 1977. Competition on marine hard substrata: adaptive significance of solitary and colonial strategies. American Naturalist 111:743-767.

Jacobs, M. W., B. M. Degnan, J. D. D. Bishop, and R. R. Strathmann. 2008. Early activation of adult organ differentiation during delay of metamorphosis in solitary ascidians, and consequences for juvenile growth. Invertebrate Biology 127:217-236.

Karlsson, B., and C. Wiklund. 1984. Egg weight variation and lack of correlation between egg weight and offspring fitness in the wall brown butterfly Lasiommata megera. Oikos 43: 376-385.

Kott, P. 1985. The Australian Ascidiacea: part I, Phlebobranchia and Stolidobranchia. Memoirs of the Queensland Museum 23:1-440.

Lambert, C. C., I. M. Lambert, and G. Lambert. 1995. Brooding strategies in solitary ascidians: Corella species from north and south temperate waters. Canadian Journal of Zoology 73:1666-1671.

Lambert, G. 1968. General ecology and growth of a solitary ascidian, Corella willmeriana. Biological Bulletin 135:296-307.

Lawrence, J. M., J. B. McClintock, and A. Guille. 1984. Organic level and caloric content of eggs of brooding asteroids and an echinoid (Echinodermata) from Kerguelen (South Indian Ocean). International Journal of Invertebrate Reproduction and Development 7:249-257.

Leishman, M., and M. Westoby. 1994. Hypotheses on seed size: tests using the semiarid flora of western New South Wales, Australia. American Naturalist 143:890-906.

Leishman, M., and M. Westoby. 1995. The role of large seed size in shaded conditions: experimental evidence. Functional Ecology 8:205-214.

Levitan, D. 2000. Optimal egg size in marine invertebrates: theory and phylogenetic analysis of the critical relationship between egg size and development time in echinoids. American Naturalist 156:175-192.

Litvak, M. K., and W. C. Leggett. 1992. Age and size-selective predation on larval fishes: the bigger-is-better hypothesis revisited. Marine Ecology Progress Series 81:13-24.

Maranon, T., and J. Grubb. 1993. Physiological basis and ecological significance of the seed size and relative growth rate relationship in Mediterranean annuals. Functional Ecology 7:591-599.

Marshall, D. J. 2005. Geographical variation in offspring size effects across generations. Oikos 108:602-608.

Marshall, D. J., C. N. Cook, and R. B. Emlet. 2006. Offspring size effects mediate competitive interactions in a colonial marine invertebrate. Ecology 87:214-225.

Marshall, D. J., and M. J. Keough. 2003. Effects of settler size and density on early post-settlement survival of Ciona intestinalis in the field. Marine Ecology Progress Series 259: 139-144.

Marshall, D. J., and M. J. Keough. 2005. Offspring size effects in the marine environment: a field test for a colonial invertebrate. Austral Ecology 30:275-280.

Marshall, D. J., and M. J. Keough. 2008. The evolutionary ecology of offspring size in marine invertebrates. Advances in Marine Biology 53:1-60.

Mazer, S. J. 1989. Ecological, taxonomic, and life history correlates of seed mass among Indiana dune angiosperms. Ecological Monographs 59:153-175.

McClintock, J. B., and J. S. Pearse. 1986. Organic and energetic content of eggs and juveniles of Antarctic echinoids and asteroids with lecithotrophic development. Comparative Biochemistry and Physiology 85A:341-345.

McEdward, L. A., and D. A. Janies. 1997. Relationships among development, ecology, and morphology in the evolution of Echinoderm larvae and life cycles. Biological Journal of the Linnean Society 60:381-400.

McEdward, L. R., and S. F. Carson. 1987. Variation in egg organic content and its relationship with egg size in the starfish Solaster stimpsoni. Marine Ecology Progress Series 37:159-169.

Moles, A. T., D. I. Warton, and M. Westoby. 2003. Do smallseeded species have higher survival through seed predation than larger-seeded species? Ecology 84:3148-3161.

Moles, A. T., and M. Westoby. 2003. Latitude, seed predation and seed mass. Journal of Biogeography 30:105-128.

Moran, A. L., and R. B. Emlet. 2001. Offspring size and performance in variable environments: field studies on a marine snail. Ecology 82:1597-1612.

Nakaya, F., Y. Saito, and T. Motokawa. 2005. Experimental allometry: effect of size manipulation on metabolic rate of colonial ascidians. Proceedings of the Royal Society B 272: 1963-1969.

Osman, R. W., and R. B. Whitlatch. 1996. Processes affecting newly-settled juveniles and the consequences to subsequent community development. Invertebrate Reproduction and Development 30:217-225.

Paulay, G., L. Boring, and R. R. Strathmann. 1985. Food limited growth and development of larvae: experiments with natural seawater. Journal of Experimental Marine Biology and Ecology 93:1-10. 
Paz, H., S. J. Mazer, and M. Martinez-Ramos. 1999. Seed mass, seedling emergence, and environmental factors in seven rain forest Psychotria (Rubiaceae). Ecology 80:1594-1606.

Paz, H., S. J. Mazer, and M. Martinez-Ramos. 2005. Comparative ecology of seed mass in Psychotria (Rubiaceae): within- and between-species effects of seed mass on early performance. Functional Ecology 19:707-718.

Perron, F. E. 1981. Larval biology of six species of the genus Conus (Gastropoda: Toxoglossa) in Hawaii, USA. Marine Biology 61:215-220.

Perron, F. E. 1986. Life history consequences of differences in developmental mode among gastropods in the genus Conus. Bulletin of Marine Science 39:485-497.

Qian, P. Y., and F. S. Chia. 1991. Fecundity and egg size are mediated by food quality in the polychaete worm Capitella sp. Journal of Experimental Marine Biology and Ecology 148:11-25.

Rasanen, K., A. Laurila, and J. Merila. 2005. Maternal investment in egg size: environment- and population-specific effects on offspring performance. Oecologia 142:546-553.

Rees, M., and M. Westoby. 1997. Game-theoretical evolution of seed mass in multi-species ecological models. Oikos 78: $116-126$.

Reitzel, A. M., C. M. Miles, A. Heyland, J. D. Cowart, and L. R. McEdward. 2005. The contribution of the facultative feeding period to echinoid larval development and size at metamorphosis: a comparative approach. Journal of Experimental Marine Biology and Ecology 317:189-201.

Russ, G. R. 1982. Overgrowth in a marine epifaunal community: competitive hierarchies and competitive networks. Oecologia 53:12-19.

Ryland, J. S., and J. D. D. Bishop. 1993. Internal fertilisation in hermaphroditic colonial invertebrates. Oceanography and Marine Biology Annual Reviews 31:445-477.

Searle, S. R., G. Casella, and C. E. McCulloch. 1992. Variance components. John Wiley and Sons, New York, New York, USA.

Sebens, K. P. 1982. Competition for space: growth rate, reproductive output, and escape in size. American Naturalist 120:189-197.

Sherrard, K. M., and M. LaBarbera. 2005a. Form and function in juvenile ascidians. I. Implications of early juvenile morphologies for performance. Marine Ecology Progress Series 287:127-138.

Sherrard, K. M., and M. LaBarbera. 2005b. Form and function in juvenile ascidians. II. Ontogenetic scaling of volumetric flow rates. Marine Ecology Progress Series 287:139-148.
Smith, C. C., and S. D. Fretwell. 1974. The optimal balance between size and number of offspring. American Naturalist 108:499-506.

Stearns, S. C. 1992. The evolution of life histories. Oxford University Press, Oxford, UK.

Stoner, D. S. 1990. Recruitment of a tropical colonial ascidian: relative importance of pre-settlement vs. post-settlement processes. Ecology 71:1682-1690.

Strathmann, M. F. 1987. Reproduction and development of marine invertebrates of the North Pacific coast. University of Washington Press, Seattle, Washington, USA.

Strathmann, R. R. 1977. Egg size, larval development, and juvenile size in benthic marine invertebrates. American Naturalist 111:373-376.

Strathmann, R. R. 1990. Why life histories evolve differently in the sea. American Zoologist 30:197-207.

Svane, I. 1983. Ascidian reproductive patterns related to longterm population. Sarsia 68:249-255.

Swalla, B. J., C. B. Cameron, L. S. Corley, and J. R. Garey. 2000. Urochordates are monophyletic within the deuterostomes. Systematic Biology 49:122-134.

Tarjuelo, I., and X. Turon. 2004. Resource allocation in ascidians: reproductive investment vs. other life-history traits. Invertebrate Biology 123:168-180.

Tejedo, M. 1992. Absence of the trade-off between the size and number of offspring in the natterjack toad (Bufo calamita). Oecologia 90:294-296.

Turnbull, L. A., M. Rees, and M. J. Crawley. 1999. Seed mass and the competition/colonization trade-off: a sowing experiment. Journal of Ecology 87:899-912.

Turon, X., and S. Lopez-Legentil. 2004. Ascidian molecular phylogeny inferred from mtDNA data with emphasis on the Aplousobranchiata. Molecular Phylogenetics and Evolution 33:309-320.

Vance, R. R. 1973. On reproductive strategies in marine benthic invertebrates. American Naturalist 107:339-352.

Westoby, M., E. Jurado, and M. Leishman. 1992. Comparative evolutionary ecology of seed size. Trends in Ecology and Evolution 7:368-372.

Young, C. M. 1985. Abundance patterns of subtidal solitary ascidians in the San Juans, Washington, as influenced by food preferences of the predatory snail Fusitriton oregonensis. Marine Biology 84:309-321.

Young, C. M. 1986. Defenses and refuges: alternative mechanisms of coexistence between a predatory gastropod and its ascidian prey. Marine Biology 91:513-522.

\section{APPENDIX A}

Volume and growth rate calculations (Ecological Archives E091-253-A1).

\section{APPENDIX B}

Measurement of total carbon content (Ecological Archives E091-253-A2).

\section{APPENDIX C}

Sample sizes and statistical results (Ecological Archives E091-253-A3). 